\title{
ADMINISTRACION DEL MARQUESADO DE LLOMBAI TRAS LA "NUEVA PLANTA"
}

\author{
Elia GOZÁLBEZ ESTEVE
}

Universidad de Alicante

Con este artículo, pretendemos, en primer lugar, hacer un escueto comentario sobre la administración territorial y local de un señorío valenciano - el marquesado de Llombai - antes y después de la expulsión de moriscos. Y en segundo lugar analizar con mayor detenimiento el gobierno del mismo a partir de la pérdida del derecho foral valenciano.

Aunque basado en un caso particular, la organización y desarrollo de los municipios que integran el marquesado puede ser representativo del ámbito valenciano, a pesar de la variedad respecto al número de oficios, cargos municipales y el modo de acceder a ellos.

El marquesado de Llombai se halla situado en la Ribera Alta, al suroeste de la actual provincia de Valencia, dentro del antiguo "Vall dels Alcalans". Los cuatro pueblos que llegaron a formar la "foya" y baronía de Llombai -Catadau, Alfarb, Llombai y Alédua- tuvieron su origen en el reparto que, de las tierras conquistadas, hizo don Jaime I entre sus caballeros (1).

En una muy breve síntesis cabe mencionar que, a través de sucesivas donaciones, herencias y ventas, los cuatro lugares fueron unificados jurisdiccionalmente con don Aymerich de Centelles a finales del siglo XIV (1391), y territorialmente un siglo después (alrededor de 1490), con don Juan de Borja, que los anexionó a la casa ducal de Gandía, con los cambios y alternativas administrativas que este hecho supuso.

Llombai contaba con dos comunidades distintas -cristianos y mudéjares- que se reflejaba en una organización local separada para unos y otros. Dicho lugar fue, desde sus inicios, el centro administrativo del señorío alrededor del cual giraban los lugares de Catadau, Alfarb y Alédua, con población exclusivamente mudéjar. Esta dualidad posibilita un estudio comparativo de las dos comunidades sumamente interesante, tanto en la cuestión administrativa como de otra índole. 
La documentación manejada evidencia un predominante absentismo señorial, ya en el siglo XIV, que se hace definitivo con la vinculación del señorío a los Borjas (2).

Obviamente, la ausencia del titular, no ya del señorío sino hasta del Reino de Valencia, obliga a delegar la autoridad de la administración territorial en un Procurador General, representante pleno del señor, que asume la totalidad de las facultades otorgadas a su mandatario por la corona, y en un Baile, responsable de la gestión económica en general y de la judicial referida a los mudéjares (3).

Es de destacar que tanto la comunidad cristiana como la mudéjar estaban en igualdad de condiciones, puesto que se hallaban bajo la autoridad del Procurador General y del Baile. Como hemos mencionado ya anteriormente, éstos estaban encargados de las diferentes funciones administrativas del señorío, a cuyo cargo accedían por designación directa del señor, al cual informaban periódicamente (4).

Sin embargo la situación era muy distinta en cuanto a la administración local, en donde se dejaba sentir la disparidad de las dos comunidades asentadas en el señorío. Así, la comunidad cristiana de Llombai tenía un justicia, dos jurados, un consejo, un almotacén, un acequiero, un "misatge", un "alcayt", un colector y varios consejeros, organigrama frecuente en los señoríos valencianos. Mientras que cada comunidad mudéjar del señorío contaba con un alfaquí, un alamín, la aljama y dos jurados (5). El alfaquí desapareció con la forzosa conversión (1519-1523), siendo asumido su cargo por el justicia de la comunidad cristiana en Llombai (único justicia que había hasta ese momento en el marquesado) y sustituido por justicias en el resto de las comunidades moriscas (6).

Con la expulsión de los moriscos (año 1609) y la consecuente repoblación (año 1611) fueron pocos los cambios que se introdujeron en la administración local y territorial del señorío. Naturalmente, quedaron anulados todos los cargos y organismos relacionados con los moriscos (aljama, alamín) manteniéndose los restantes (justicias, jurados, almotacén, consejo, etc...).

Lamentablemente, las cartas-pueblas analizadas son copias incompletas del XVIII y no hacen ninguna referencia al gobierno, administración y regulación de la vida corporativa y comunitaria del señorío durante el siglo XVII (7). No obstante, todo hace suponer que, en el momento de la repoblación, se designaron en el marquesado los cargos habituales en las localidades valencianas, dejándose para posterior deliberación los pormenores de los mismos.

Como quiera que fuese, nos consta que en la misma fecha del otorgamiento de las cartas-pueblas se concedió a los citados cargos y consejo general la facultad de ordenar capítulos concernientes "al bon regiment y gobern". Usando de la facultad que se les otorgaba, en Catadau redactaron unas ordenanzas compuestas de cincuenta y un capítulos (año 1613). Presentadas al Procurador General, las aceptó previa advertencia de que el citado documento no debía contradecir los capítulos contenidos en los "autos de la población y concesión de jurisdicción" (8).

La extensa temática que encierran estas ordenanzas, destinadas a paliar anterio- 
res deficiencias, nos permiten conocer los cargos de la administración local -justicias, lugartenientes, almotacén, guardia y acequiero- así como sus funciones, competencias, actividades, etcétera. Su detallada exposición es claro indicio de una voluntad ordenancista que trata de regular con mayor precisión la fisonomía del nuevo orden municipal.

Sin pretender profundizar en el tema, es muy significativa la minuciosidad que adquieren en algunas cuestiones, como las referentes a las regalías o a las relacionadas con algunos productos agrícolas comercializables (por ejemplo, la hoja de morera, indispensable para la elaboración de la seda), quedando así de manifiesto cuáles eran las preferencias señoriales en ese momento.

Pese a las reservas que esta cuestión nos merece, debemos reparar en que la administración local adquiere una cierta autonomía, que le hace capaz de proporcionarse normativas orientadas a salvaguardar sus intereses, básicamente contra hurtos y daños ocasionados por los mismos vecinos, sus ganados o sus cabalgaduras, y que son sancionados con diferentes penas (9).

La similitud con otras ordenanzas, como las autorizadas en Oliva en 1614, nos evidencia que las carencias de normativas detectadas en las cartas-pueblas del marquesado no son algo excepcional (10).

Por último, a pesar de que estas ordenanzas municipales se refieren sólo a Catadau, hay indicios de que los otros lugares se regían por una normativa similar.

$* * * * * * * * * * * * * * * * * *$

El siglo XVIII fue testigo de importantes cambios en el ámbito valenciano. Los conflictos, que ya desde sus comienzos se entablan, serán, por sus consecuencias, decisivos en la evolución posterior de este reino, tanto política, social como económicamente.

Resulta innegable que la Guerra de Sucesión tuvo dramáticas consecuencias en el Reino de Valencia, por la pérdida de sus más importantes y significativos derechos. Como era de esperar, las consecuencias de la derrota se hicieron notar con mayor fuerza en aquellos lugares que se habían distinguido por su apoyo a la causa del Archiduque, pero en general las cuotas de autonomía constitucional y fiscal del reino quedó bastante mermada.

La pérdida del derecho foral valenciano, junto con la centralización administrativa y, en consecuencia, la introducción de las leyes castellanas (11), tuvo también sus repercusiones a nivel local: en el ducado de Gandía y en el marquesado de Llombai, como en los demás lugares de señorío o realengo valencianos, fueron modificadas las instituciones municipales (12). Estas instituciones merecen una atención especial ya que, a pesar de ser implantadas por la fuerza y bajo un significativo control señorial, no impidieron que en algunas ocasiones los pueblos pudieran defender los derechos de los vasallos contra el señor 
Con la nueva organización municipal el consejo, el justicia, los jurados y el almotacén desaparecen, implantándose el ayuntamiento regido por los capitulares y presidido por un alcalde.

En lo que atañe al marquesado de Llombai, el carácter uniformista del nuevo régimen fue decisivo en el desarrollo de los acontecimientos del siglo XVIII (13). Afortunadamente hemos hallado "Las normas para el buen gobierno del marquesado", confeccionadas a raíz del juicio de residencia de 1725 encomendado al doctor don Antonio Vicente Giménez del Olmo, abogado de los Reales consejos, gobernador, justicia mayor y juez de residencia del marquesado (14).

Son muchas las posibilidades que los juicios de residencia ofrecen para el estudio de la administración señorial, así como la relación existente entre la administración real y la señoríal, abordada magistralmente por González Alonso (15). En nuestro caso, las Normas de 1725 nos permiten acceder al conocimiento y desarrollo de la administración municipal de los lugares de señorío en un momento crucial.

Según Carrasco Martínez "la residencia es un mecanismo periódico y regular, que se ejerce sobre todos los oficiales de un concejo por delegados de la autoridad superior para examinarlos de la responsabilidad contraida con los oficios e inspeccionar las cuentas del municipio" delimitando las características diferenciales entre residencia, pesquisa y visita. Respecto a la visita, precisa que la inspección se pone en marcha por la existencia de indicios de irregularidad en el desempeño de un oficio o el funcionamiento de una institución (16). Parece ser que el procedimiento de inspección realizado en el marquesado se ajusta a este mecanismo de examen y responsabilidad pese a que se le denomina juicio de residencia (17).

Giménez Chornet, en su estudio sobre el juicio de residencia de Cabanes (1728), insiste en que las residencias no se efectuaban cuando se producía un cambio en el gobierno del municipio sino cuando el señor creía oportuno realizar una inspección, bien a raíz de alguna denuncia o simplemente por acentuar el control sobre los oficiales locales. Cabe la posibilidad de que, tanto en el marquesado de Llombai como en Cabanes, los términos visita, residencia o pesquisa, fuesen tomados como sinónimos (18). Situación bastante frecuente según Carrasco Martínez ya que "gran parte de la bibliografía, sobre todo las aportaciones de historiadores del derecho, se han dirigido a delimitar las diferencias, muy sutiles a veces entre juicio de residencia, visita y pesquisa, pero ni en España ni en Indias los procedimientos se efectuaron tan escrupulosamente ni parece que la preocupación de la administración fuera primordialmente de orden técnico-jurídico" (19).

En el marquesado de Llombai sólo conocemos el cierre del proceso de inspección a través de las "Normas para el buen gobierno del marquesado". Constan de treinta y siete capítulos mediante los cuales el juez de residencia intenta subsanar las irregularidades detectadas. Su contenido manifiesta la intención de erradicar ciertos abusos de tipo económico, por parte de los componentes del ayuntamiento en su beneficio y en el del sector social más acomodado, así como recordar las nuevas leyes, control, funcionamiento y organización de la administración municipal. 
No nos consta que los residenciados acudiesen a la Audiencia ni que se opusieran a ella por la vía señorial tal y como documenta acertadamente Pla Alberola para el condado de Cocentaina, actitud que hace extensible cuando afirma que "el derecho de visita era motivo de una enconada pugna, y no sólo en los lugares de señorío." (20).

Sin entrar en la intrincada problemática que ofrece tanto la figura del juez de residencia como la residencia en sí, y que no es materia de nuestro estudio, sí que hay que indicar cuáles fueron las cuestiones preferentes en el marquesado, sólo hasta cierto punto indicativas ya que, generalmente, los juicios de residencia se ceñían a un esquema bastante común para todos los señoríos.

En primer lugar, el juez de residencia del marquesado dirige su atención hacia el ayuntamiento, tanto al recinto en donde se reunen los capitulares como a sus componentes. La sede del ayuntamiento adquiere importancia, puesto que las normativas encaminadas a la restauración de la casa consistorial en el marquesado se multiplican. Obviamente su deterioro dañaba la imagen del señor, del cual emanaba el poder que éste representaba.

El juez de residencia, don Antonio Vicente Giménez del Olmo, en atención a que la sala capitular se hallaba en pésimo estado "sin asientos ni bufetes" ordena su inmediata restauración (Cap. XXXV) para que sea punto de reunión irreemplazable y decoroso, haciendo notar la relajación de costumbres en cuanto a su utilización con frases como "no se pueden zelebrar los ayuntamientos privadamente en las casas de los capitulares como asta esta residenzia menos bien an practicado, sí que prezisamente a de ser en la cassa del cavildo presidiendo el governador o su teniente en su ausenzia o enfermedad..." (cap. UI) o "por la grande autoridad y representazión que tiene el ayuntamiento, y lo poco que asta aquí se a preziado en esta villa, mando que los capitulares bengan a él con la mayor dezenzia y conpostura que sus medios alcanzaren, y no con el pelo atado, en cuerpo, con garrotes y cañas, so pena que no se les admitirá ni dará asiento..." (cap. IV).

Pero ni las nuevas instituciones ni el juicio de residencia debieron alterar significativamente estas costumbres, puesto que años más tarde (1756) don Francisco Benlloch, como gobernador del marquesado, se queja de que "siempre se han observado las costumbres en los pueblos por municipales estatutos, y tradiciones, que no han consentido por la mutación de los tiempos, y genios la introducción de operaciones rethóricas, y de la moderna, y bien culta política"; insistiendo en la importancia que tiene la apariencia externa de los capitulares y lo poco que éstos reparan en ello, puesto que "para la respetable ceremonia de un ayuntamiento aún conservan la montera los oficiales, cuando hay providencias de el Reino que las prohibe, aún se juntan con paños menores que incitan vascosidad al que político les mira".

El juez de residencia perfila la legislación existente respecto a las sesiones del ayuntamiento, ordenando que no se admita ninguna persona extraña "que no sea alcalde, regidor o alguazil mayor de los que tienen voto en él...", excepto, claro está, en caso de ser llamados. Concretamente, el procurador síndico, cuya función era la de cuidar del bien común "al mayor veneficio de los pobres..." y "negociar las cau- 
sas pendientes" (cap. XXXIII), debe ser citado con antelación y puede estar presente siempre que el asunto a tratar pueda "gravar y perjudicar a la comunidad de vezinos, pero en las funziones públicas en que asiste la villa no tiene asiento preziso ni lugar entre los capitulares, sí empero el escribano del ayuntamiento" (cap. IV). Obviamente, la presencia del escribano era imprescindible ya que su función consistía en "escrivir todos los repartimentos cuentas de haveres reales y propios, libramientos, acuerdos, autos de avastos, posturas..." así como las multas, gastos de justicia, obras pías y públicas (cap.XXXVI).

Todas estas normativas vienen encaminadas principalmente a evitar que los componentes del ayuntamiento se reúnan fuera de él, lo cual parece ser que era frecuente, siendo esta una de las causas que motivaron el juicio de residencia ya que con ello, irremediablemente, se producía una fuga de control que el señor no estaba dispuesto a tolerar.

Es de suponer que con el mismo propósito se obliga a la organización del archivo, insistiendo en la necesidad de un armario en la sala capitular para este fin, con tres llaves que salvaguarden su seguridad (cap. V), pormenorizando una larga lista de los documentos que deben ser guardados en él (cap. VI) así como los trámites para su utilización, con el fin de garantizar el secreto de las deliberaciones y facilitar el acceso del señor a los mismos (cap. VII).

En cuanto a los componentes del gobierno municipal, las Normas de 1725 insisten en que la elección de oficios es facultativa del duque de Gandía y que su nombramiento debe hacerse público en la sala capitular, reunido el pleno del ayuntamiento. Los oficiales electos deben jurar su cargo ante el gobernador "por ser acto de jurisdizión que se deve exerzer en dicha cassa..." (cap. I). Los nuevos oficiales deben nombrar cuatro repartidores para que "empadronen y repartan los haveres reales que cupieren a esta villa según las ordenes de su magestad...". Así mismo, se prevé que se nombren dos diputados del ayuntamiento para tomar las cuentas "de los repartimientos y rentas de propios, guardas de frutos y heredades, portero del ayuntamiento, alcayde de la cárzel, mayordomo de propios, rezeptor de penas de cámara y demás condenaziones, rezeptor del papel sellado y de la bula de la Santa Cruzada, beedores de daños y justiapreziadores de tierras y edifizios, depositario del trigo del pósito y los demás oficiales que la villa acostumbra nombrar". Esta cita aporta una expresiva relación del aumento del número de cargos que componían el nuevo ayuntamiento.

Desgraciadamente desconocemos los criterios del señor para la elección de los oficiales en el marquesado. La documentación manejada trasluce que se le presentaba una lista con los candidatos y que éste, o su representante más inmediato, elegía a los más idóneos para sus intereses. Es de suponer que los requisitos fuesen similares a los de la época foral, en la que se exigia, para ser oficial del marquesado, que los designados no tuviesen deudas y que hubiesen transcurrido dos años desde que desempeñaron el cargo para el que eran aspirantes (ordenanzas 1613, caps. XLVII XLVIII) (21). 
Referente a los alcaldes ordinarios, cada municipio del marquesado -Llombai, Catadau y Alfarb- tenía uno. Nombrados por el duque de Gandía o su delegado, desempeñaban un papel meramente representativo con un poder muy limitado a raíz de la merma de sus competencias en beneficio del gobernador(22).

Como era previsible, el excesivo control de los gobernadores en las tierras sometidas a regimen señorial fue un continuo motivo de quejas por parte de los alcaldes ordinarios, capitulares y vasallos ya que, en general, esta situación les imposibilitaba influir más significativamente en el desarrollo de la vida económica y social de sus lugares.

La aludida restricción de competencias de los alcaldes ordinarios es contundente en las Normas de 1725. Dice el juez textualmente: "los alcaldes d'esta villa se contengan en su jurisdicción pedánea sin exerzer ni usurpar la ordinaria admitiendo demandas de más cantidad de seiscientos maravedís, que valen doze reales d'esta moneda con poca diferenzia, ni forme autos en causas ziviles y criminales en más de lo que les es permitido por derecho, que es prender los delinquientes, entregarlos con las diligenzias que ubieren ejecutado en sumario al governador que ejerze la jurisdicción ordinaria que nativamente compete a su excelencia marqués y dueño d'este estado; y lo cumplan pena de doszientas libras para la cámara y de la nulidad de todos los autos y diligenzias que en otra forma executaren, con las demás prevenidas por derecho" (cap. XXIX).

Parece ser que estas limitaciones ejecutivas del alcalde ordinario fueron motivo de fricciones, puesto que unos años después, en 1731, tanto los alcaldes como los vasallos manifestaron judicialmente su descontento (23). El gobernador don Francisco Benlloch, en 1756, insiste en la conflictividad de este cargo: "llámanles ordinarios, sobre cuya circunstancia de voz, porque en las elecciones no viene más que el puro nombre de alcalde sin la voz adjetiva de ordinario, protestan todos los años los nuevos electos la posesión y uso de la jurisdicción ordinaria por quanto por la Real Sala en juicio contradictorio de possesión y prescripción de el largo usso contra los títulos dominicales, tienen determinado usen dichos alcaldes de la jurisdicción ordinaria en lo civil, y en la criminal solo el governador el mero imperio, pero esto por mal defendido el estado, y no hechose cargo de los títulos de el Marqués de Lombay, cuyas razones en sí reserva el governador autor de estos comentarios que se pudieran alegar aun en el pleyto de propiedad en que dejó la Real Sala el derecho a paz y salvo" (24).

Referente a los regidores, el juicio de residencia delimitó sus funciones y obligaciones, instándoles a visitar con frecuencia las regalías, controlar las pesas y medidas y la calidad del género, dejando en tales lugares, por escrito y en lugar visible, un arancel, precisando en el mesón que se debe acordar de antemano "al precio que deve vender la paja, zevada y algarrovas y alquiler de las camas cuya diligenzia executarán cada mes o siempre que sea necesario" (cap. XXX), a la vez que se insiste en que los regidores deben ser equitativos y "no gravar a unos y exonerar a otros" bajo la pena de pagar los daños que se ocasionasen (cap. XXXI). 
Con la supresión del derecho foral no se podía eliminar de raíz todos los cargos existentes en los municipios, por lo que se tuvieron que apoyar en los mismos, limitándose en algunos casos al simple cambio de nombre. Tal es el caso del almotacén. Sin pretender analizar a fondo la cuestión, recordemos que en las ordenanzas de 1613 el almotacén es centro de atención en muchos de sus capítulos. Como encargado de la policía urbana controla las transacciones comerciales, inspecciona la panadería, tienda y taberna (cap. XXXV) y supervisa las compras de bastimentos (cap. XXXV y XXXVI). Con amplia libertad de gestión, es depositario de pesas, medidas y de controlar las ganancias de los encargados de las regalías. Pues bien, las nuevas instituciones hacen recaer estas mismas funciones sobre el regidor mayor, tal y como queda reflejado en las Normas de 1725 y en el sustancioso comentario que hace don Francisco Benlloch, buen conocedor de la importancia del funcionamiento administrativo, al cual dedica una parte importante de su obra, encaminada a desentrañar las competencias de los cargos locales (25).

Las instituciones borbónicas mantuvieron sus exigencias tanto en cuanto a la calidad de la gestión como en cuanto a la capacidad intelectual y humana de los gestores. De ahí su esmero en la elección de los regidores mayor y menor, exigiendo "se mire sean hombres arraigados para el manejo de los caudales". Respecto a la delimitación de sus competencias, don Francisco Benlloch precisa que "el mayor obtiene en sí el cargo de almotacén y fiel medidor por tener la preheminencia de aforar los mantenimientos, ajustar las pesas y medidas, con el carácter de común depositario y colector de los caudales reales y concejiles que anuales se acopian por repartimiento". Matizando que el "menor tiene el mismo cargo, honores y preheminencias que el mayor, pero en ausencias de el mayor sólo privativamente logra el ser colector de los derechos reales de las tierras havientes forasteros" (26).

En un comprensible afán de incrementar las rentas señoriales y de proteger sus intereses y el de los vasallos, los oficiales del señorío, al redactar las ordenanzas de 1613, dedicaron especial atención a la imposición y cobro de multas, primordialmente las impuestas con relación a las regalías, siendo repartidos sus beneficios con la misma proporcionalidad que antes de la expulsión.

Con las nuevas normativas se mantiene una cierta continuidad en el reparto de los ingresos provinientes de las multas en metálico, salvo alguna excepción, puesto que nos consta que, en la época foral, el almotacén era el único beneficiario de las penas pecuniarias impuestas por delitos de su incumbencia, y con la Nueva Planta, sólo es beneficiario del tercio "de las penas que cogiere de la carne, tiendas, panaderías, y cosas que están sujetas al aforo por el número, peso y medida" (caps. XXXVIll- XXX1X- XLlll-Ll) (27).

Además de los cargos citados, cada pueblo tenía un síndico procurador general cuya función era la de cuidar del bien común y negociar las causas pendientes. Un alcalde de huerta encargado de rondar el término, cuidar que los campos, caminos y montes estuviesen limpios y en buenas condiciones, vigilar que los ganados no 
dañasen los cultivos e imponer las penas que estableciesen los ayuntamientos o el gobernador. El juez de residencia se reitera en las competencias de los alcaldes y alguaciles mayores "por ser obligación de sus oficios", les amonesta por la falta de celo en su cargo y pormenoriza las obligaciones del alcalde de la cárcel, recordándole que su ocupación era la de tomar nota de las entradas de los presos, la causa de su encarcelamiento, el nombre del juez que les mandó prender, los bienes que traían consigo, así como el día mes y año de la entrada y, con la misma exactitud, la fecha de su puesta en libertad (cap. XXXVII).

El cargo de teniente de alcalde era similar al denominado en Castilla alguacil mayor, cuya responsabilidad consistía en ejecutar las órdenes del alcalde, su superior, controlar la asignación de los cargos concejiles, así como suplir las ausencias del alcalde de acuerdo con el regidor mayor(28).

Respecto al acequiero, Benlloch destaca su importancia dentro de la comunidad. Señala, de entre sus muchas competencias, la de adjudicar adecuadamente las aguas de los tres términos, regular los días y los campos que correspondía regar, con idénticas atribuciones y obligaciones que en la época foral (29). Para el mejor control del sistema de riegos cada ayuntamiento nombraba un acequiero y un subacequiero que distribuían las aguas por los brazos y regaderas provenientes de la acequia principal. El acequiero estaba facultado para multar según las ordenanzas municipales a quienes "falten al turno de el riego hurtan el agua, ensuzian la zequia, paran el agua con lodo o la dejan perder sin bolberla a la cequia común...". Con las nuevas instituciones el importe de las multas se distribuye equitativamente entre acequiero, subacequiero y "cámara", mientras que en el período anterior, sólo el acequiero era el destinatario del total de los ingresos provenientes de la multas relacionadas con el dispositivo de las aguas y su distribución (del cap. XXI al XXIX) (30).

$\mathrm{Al}$ igual que en otros temas, este minucioso gobernador que fue don Francisco Benlloch nos facilita una fuente inagotable de datos respecto a la organización del marquesado, deteniéndose pacientemente en deslindar con precisión cargos, obligaciones y derechos. No hay duda de que tal rigor en su exposición se debe a que la organización municipal introducida por los Borbones fue novedad difícil de asimilar, y de ahí la necesidad de una descripción detallada así como de alusiones a lo que equivalen tales cargos en Castilla, de donde fueron tomados. Posiblemente, esta pudo ser la intencionalidad del gobernador, don Francisco Benlloch, pero también es cierto que en Castilla, concretamente en los señoríos perteneciente a la Casa del Infantado, los juicios de residencia del XVIII insisten en cuestiones muy similares a las aquí expuestas puesto que "se cubren vacíos legales, se perfecciona la legislación ya existente y se delimitan las competencias de los diversos oficios concejiles". Lo cual nos induce a pensar que lo que a primera vista podría parecer un marcado interés por dar a conocer e implantar el nuevo sistema municipal, tiene también otra lectura, ya que lo que hace el juez en la residencia efectuada en el marquesado -en la que nos hemos apoyado para determinar los cargos y competencias que la nueva 
monarquía había introducido en el señorío- es insistir en una serie de medidas, legislativas y ejetucivas, habituales en estos procesos de inspección, al igual que en Castilla (31). Por ejemplo los juicios de residencia aprovechan la inspección para recordar y vitalizar los cargos concejiles; pero, obviamente, la introducción de innovaciones tanto en términos generales como en la esfera local, suponían unas dificultades añadidas, por lo que concluye el juez de residencia con la orden de que todas estas normas citadas "queden en el ayuntamiento y archivo desta villa un auto autorizado deste auto y que se lea a los capitulares en cada un año, luego que fueren admitidos a sus oficios poniendo fee a su continuazión de haverlo ejecutado para que no puedan alegar ygnorancia".

Dentro del régimen señorial, la administración de justicia es una de las funciones más importantes. Como tal, el señor la reserva para sí y sólo en su ausencia la cede a su reprensentante más inmediato, bien se trate del procurador, el gobernador, el baile o el alcalde mayor.

Durante los siglos XV y XVI, en el marquesado, el procurador general residente en Valencia es el representante pleno del señor. Goza de cláusula abierta, facultad que le permite nombrar nuevos procuradores en casos especiales, por ejemplo procurador para pleitos; pero, sobre todo, le da potestad para ampliar sus competencias (32).

Después de la expulsión de los moriscos, la documentación manejada sólo hace referencia esporádicamente al "Procurador y Bal.le General", y de forma un tanto confusa, lo cual nos hace suponer que se trataba de una sola persona, superior a los cargos locales del señorío (33).

Pero lo que nos interesa resaltar ahora es que en los momentos iniciales de la Nueva Planta las formas de la administración cambiaron más en la teoría que en la práctica, puesto que la pretendida ruptura drástica con las instituciones forales fue inviable en los primeros años; y aún después, en algunos aspectos, hubo cierta continuidad. A este respecto, resulta sumamente interesante comprobar como en el marquesado, las amplias prerrogativas concedidas al gobernador en la época postforal son muy similares a las otorgadas al Procurador General en las ordenanzas de 1613, aunque al nuevo gobernador se le exige una gestión más precisa y directa, lo que actualmente denominaríamos mayor profesionalidad (34).

Según Benlloch, "goza este empleo de el alto mero y mixto imperio de la Baronía despoblada de Alhedua por honor no más, porque como no hay vecinos, ni poblado, careze de sujeto sobre quien recaiga esta jurisdicción. De los tres pueblos de el mero imperio goza en lo criminal, y en lo civil de el mixto á prevención con los alcaldes que se dicen ordinarios por esta causa y en los casos de jurisdicción alphonsina, sobre que no se pueden formar autos.

Tiene dicho Ggovernador facultad en todos los ayuntamientos y actos públicos que ocurren con precisión en Lombay, y de voluntad en los demás pueblos si urge la necesidad..."(35). 
La influencia del gobernador en los ayuntamientos era decisiva. Controlaba cualquier actuación de los alcaldes ordinarios cuya elección, en muchos casos, podía manipular, y resultaba imprescindible su presencia, o la de su representante, en los plenos municipales (36).

Parece evidente que el gobernador disfrutaba de prestigio y autoridad, participando en el control de los repartimentos y mediando en las desavenencias entre capitulares. Facultado para administrar justicia en primera instancia, resolvía los problemas entre los vasallos puesto que "admistra y distrubuye la justicia a quien la pide; y gobierna en lo político quanto ocurre con el carácter de alcalde mayor, que llaman aquí" (37).

Los capítulos de "Buen gobierno y régimen del marquesado de Llombai" redactados y mandados observar (19 julio 1734) por don Francisco Luis García de Villanueva, gobernador y justicia mayor, tendentes a salvaguardar la moral y las buenas costumbres, nos ratifican en la ya aludida amplitud de facultades de que gozaba este cargo. (38)

Los gobernadores solían ser forasteros nombrados por el señor y estaban obligados a residir en el marquesado para controlar directamente los derechos de su titular. Su cargo tenía una duración aproximada de 3 a 4 años y, en alguno de los casos analizados, pasaban posteriormente a ejercer alguna función administrativa en Gandía, de donde procedían algunos de ellos, o a ser gobernadores en algún otro señorío perteneciente al duque de Gandía, como Cofrentes, cargo más importante por ser cabeza de gobernación. Se da la circunstancia de que el gobernador de Cofrentes tenía un salario más reducido, quizá compensado por otras aportaciones de los vecinos o del señor. Compensaciones que también se daban en el marquesado, según se desprende de la queja del gobernador don Francisco Benlloch, por habérsele privado del disfrute del huerto agregado a gobernación, cuya renta compensaba su salario. (39).

La relación de las rentas del XVIII (cuadro $\mathrm{n}^{\mathrm{0}} 1$ ) recoge los nombres y salarios abonados a los gobernadores, insistimos, compensados en muchas ocasiones con ingresos procedentes de sus diversas actuaciones.

Sabemos que era facultativo del señor trasladar al gobernador de un señorío a otro según sus necesidades y conveniencias, y a este respecto nos parece de interés el estudio que hace Roldan Verdejo sobre la permanencia de algunos cargos administrativos en Castilla, tendentes a profesionalizarse a partir del XVIII (40). Salvadas las distancias, que obviamente las hay, es significativa la burocratización del oficio de alcalde mayor en el realengo y en los señoríos. Tanto al señor como al Rey les interesa mantener en su cargo a delegados de confianza diestros en su función. 


\section{CUADRO NN. 1}

\section{Gobernadores del marquesado (siglo XVIII)}

\begin{tabular}{|c|c|c|}
\hline Años & Nombre & Salario \\
\hline 1705 & 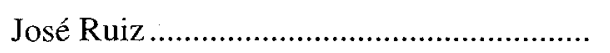 & - \\
\hline 1710 & Juan de Lago ........................................... & - \\
\hline 1720 & 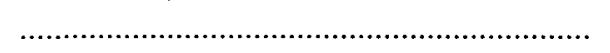 & 146 Libras \\
\hline 1734 & 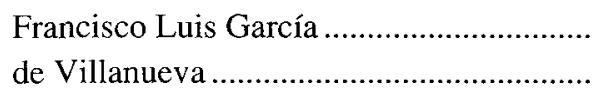 & - \\
\hline 1743 & Carlos Dolz ......................................... & $146 \mathrm{~L} .13 \mathrm{~s}$. \\
\hline $1749-53$ & 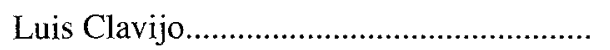 & 146 L. $13 \mathrm{~s} .4 \mathrm{~d}$. \\
\hline $1753-57$ & 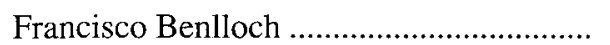 & 146 L. $13 \mathrm{~s} .4 \mathrm{~d}$. \\
\hline $1757-60$ & $\begin{array}{c}\text { Josep Santonja.......................................... } \\
\text { sube el sueldo el día que tomó posesión). }\end{array}$ & $200 \mathrm{~L}$. (se le \\
\hline 1762 & Manuel García Pescador .......................... & $200 \mathrm{~L}$ \\
\hline $1764-67$ & Josep García...... & $200 \mathrm{~L}$. \\
\hline $1797-99$ & $\begin{array}{l}\text { Vicente Sarrió Gaus ................................. } \\
\text { (contabilizado su salario con el del alguacil }\end{array}$ & $280 \mathrm{~L}$ \\
\hline
\end{tabular}

Enrique Giménez matiza ese proceso de burocratización del alcalde mayor en el realengo valenciano durante el XVIII (década de los noventa), al afirmar que "el càrrec entrà en un sistema escalafonat existent per a tot el territori de la monarquia, incardinant-se en un procés de normalitat burocrática que responia als criteris jurisdiccionalistes impulsats per Campomanes Roda en els anys seixanta i setanta" (41).

Ambas apreciaciones son aplicables a la trayectoria de los gobernadores del marquesado, dado que la organización administrativa del señorío reproduce lo que es un corregimiento y los cargos que los forman son equiparables.

En el marquesado los gobernadores no siempre fueron doctores en derecho, como recomienda don Francisco Benlloch -"conviene esencialmente y por precisión sean los gobernadores juristas muy experimentados"- prototipo de gobernador, al que con tanta frecuencia nos estamos refiriendo, por su inestimable aportación y personalidad cuidada e ilustrada, muy de acuerdo con la época (1756), defensor de los intereses de su principal y fiel partidario de la nueva política a la que califica de "moderna y bien culta" (42).

En cuanto a la autonomía local, pese al estricto control del señor sobre los municipios y sus términos, en ningún momento éstos pierden el poder para gestionar el patrimonio de la comunidad de vecinos, los abasteciminentos y los diversos servicios municipales (43).

La gestión municipal del marquesado es motivo de especial atención en el juicio de residencia de 1725 . Se exige mayor transparencia en el arriendo de los abas- 
tos, boalares y rentas de propios (cap. XXI), precisando, en este último caso, que es el mayordomo de propios el responsable de la gestión (caps. XXII y XXIII) al cual deben controlar dos capitulares para que los gastos sean los justos $\mathrm{y}$ en beneficio de la comunidad ya que, hasta este momento, se aprecia corruptela en la gestión, por lo que se dan normas precisas sobre el modo correcto de realizar las posturas: "porque no tengan los perjuicios que asta ahora se han experimentado por haver echo los remates de avastos propios privada y clandestinamente sin ninguna de las solemnidades expresadas y a contemplazión sin atender la utilidad del común de vecinos"; instanto a los procuradores sindicos a que en los "remates de propios y abastos" se extreme la trasparencia (cap. XXXIII). Por otra parte, se le ordena recaudar las deudas, tanto las contraídas en el transcurso de su gestión como las pendientes durante el mandato de su antecesor, así como finalizar los pleitos en curso (44).

El juez de residencia, comisionado por el duque de Gandía, persigue los posibles abusos en la utilización del poder por parte de los componentes del ayuntamiento, hallándoles culpables de engaño en la utilización de los fondos de propios, sin que podamos determinar su volumen, según se desprende de la siguiente cita: "porque se an reconocido en esta residencia los exzesivos gastos y salarios que de propios han pagado a los procuradores síndicos y a otras personas del ayuntamiento con el pretexto de haver ydo a negozios de la villa a la ziudad de Valencia...". El elevado coste de los salarios de procuradores síndicos y otros miembros del ayuntamiento por viajes relacionados con los bienes de propios, con el pretexto de que eran por cuestiones referentes al municipio, cuando se sabía que la mayoria eran por negocios privados, obligó a un detallado control de estos desplazamientos comisionados (cap. XXXIV) (45). Aunque es conveniente matizar que las malversaciones, abusos, favoritismos y mala gestión en este tipo de bienes era muy frecuente, por lo que los jueces de residencia, reiterativamente, dan normas detalladas sobre la forma de realizar correctamente los gastos del dinero de propios en los señoríos castellanos, en términos muy similares a los aquí expuestos.

Los servicios municipales también son objeto de una minuciosa normativa en 1725, gracias a la cual podemos apreciar el interés del nuevo regimen en dotar a los capitulares municipales de una variada gama de atribuciones para "asegurar los suministros de todo tipo, velar la calidad de los alimentos, controlar los precios e inspeccionar las instalaciones", exigiéndoles eficacia y honestidad en el desempeño de cada función, tal y como quedó expuesto anteriormente al citar a los justicias y regidores (cap,. XXX y XXXI).

Adolfo Carrasco, en un excelente estudio al que nos hemos referido repetidas veces, explica como las exhortaciones a cumplir con los deberes de abastecimiento y su incumplimiento aparecen frecuentemente, lo cual "hace pensar en que la fuerza de la costumbre era generalmente aceptada como para no ser doblegada por las codificaciones legales y suficientemente útil como para asegurar los suministros básicos". Añadiendo el mismo autor que era en la administración de los pósitos donde las irregularidades se muestran más graves (46). 
En una economía de autosubsistencia, el control de los graneros públicos se convertía en tema prioritario, a tenor de lo cual en el marquesado se inspecciona y denuncia su mal funcionamiento: "en quanto esta villa a tenido pósito y caudal de trigo para panadear y vender a los vezinos y la negligenzia, descuido y omisión de los capitulares a traído a favor miserable estado este caudal que no se [ha] hallado tan solo quenta de él exzepto veynte y tres obligaziones que se an recojido en esta residenzia a costa del mayor desvelo siendo justo se procure en todo el alivio de los pobres..."; haciendo notar que el caudal es imprescindible para que en los meses de la siembra los precios sean moderados, instando a los deudores a que salden sus deudas y añadiendo: "se a de ejecutar lo referido con tal prezisión que en su defecto será de cargo de los capitulares procurador síndico la quiebra e ynterés y demás penas prevenidas en la ley nona, título quinto del libro séptimo de la Nueva Recopilación, en conformidad de la qual se a de administrar y venefiziar dicho caudal" (cap. XXIV). Para un mayor control se ordena a los diputados de cuentas que se las tomen al depositario del trigo (cap. XVIII)(47).

Entre los suministros básicos sujetos a inspección, como era la sal, se detectaron ciertas negligencias por lo que el juez de residencia, después de las diligencias oportunas, acusa a los "justicias y regidores", entre otras cosas, de lentitud y omisión al sacar la sal del acopio, al repartirla, cobrarla y al hacer los pagos en el tiempo y plazos convenientes, ordenando "que los capitulares luego que sean admitidos a sus ofizios, saquen la sal y la conduzcan y hagan que los repartidores la distribuyan entre los vezinos según consumo de personas, ganado y cavallerías y el gasto de conduzirla, repartirla y cobrarla se prorratee por zelemines..." (cap. XVI).

La fiscalidad llevada a cabo por un complejo aparato administrativo, no sólo descubre corruptelas y descuidos sino que, además, anula prebendas. Por ejemplo, a partir de la repoblación, concretamente en Alfarb (año 1612), nos consta que el justicia y jurados, previa licencia, gozaban de autonomía por el tiempo de dos años para imponer sisa en la carne y en la extracción de frutos de dicho lugar, seguramente en previsión de los momentos difíciles a los que se enfrentaba la nueva comunidad (48). Pues bien, las normas de 1725 anulan la sisa en el abasto de la carne en general, aduciendo que no consta su autorización, al menos en la villa de Llombai, y que con ella sólo eran gravados los pobres (cap. XXVIII), queriendo así justificar esta restricción de arbitrios que, lógicamente, iba en detrimento de la economía municipal (49).

$\mathrm{Y}$ otro tanto sucede con los censales que responde Llombai, pues se denuncia que se distribuyeron los capitales entre distintos vecinos, sin obrar en beneficio del común que después pagaba el interés. Por ello se ordena a los "capitulares y al procurador síndico en nombre d'esta villa vayan judizialmente contra las personas que perzibieran dichos capitales, sus herederos, terzeros poseedores de los vienes de aquellos, restituyan las cantidades que respectivamente perzivieron y se rediman con ellas los zensos menzionados..." (cap. XXV) o que reconozcan sus deudas mediante escritura pública (cap. XXVI). Años más tarde el gobernador don Francisco Benlloch analiza los censos impuestos "en el siglo pasado por los procu- 
radores syndicos de la villa para socorrer las necesidades del pueblo". Puede que sean los mismos, pero el gobernador imputa la no devolución al elevado número de implicados y a lo confuso de la situación y no a su mala fe, puesto que "se presume que se llegaron a perder, por cuanto los acreedores herederos ignoran la situación y los deudores no saben a quien pagar" (50).

Inevitablemente, la imposición de las leyes castellanas, sobre todo las que afectaban a una mayor fiscalidad real, fueron difíciles de asimilar tal y como se desprende de las siguientes citas: "en materia de repartimentos, benefizios y cobranza de haveres reales se observen puntualmente las ynstrucciones dadas por los superintendentes d'este el año de diez y ocho en adelante y por ser muy conformes a las leyes, que no se an observado afectando no haver compreendido su entendimiento y para que no les pueda escusar esta afectada ygnoranzia de aquí en adelante se ará clara su ynteligenzia y fázil reduzirlas a la práctica, estilo y norma con que las observan los pueblos de Castilla, guardando la yndividualidad, formalidad y distinzión de los capítulos siguientes..." (cap. VIII). Acto seguido el juez analiza y puntualiza con detalle el contenido del "equivalente" y los trámites de su recaudación: "por cada puerta veynte y zinco reales...", denunciando las injusticias hechas hasta el momento (cap. IX) y tomando medidas para su justa y eficiente recaudación (cap. X). Se precisa "que la separazión de dévitos se aga sacando del todo del equivalente todo lo que ynportare el ocho por ziento de los terratenientes y lo que quedare se divida en zinquenta partes yguales, las ocho se aplicarán al servizio ordinario y extraordinario, las veynte y tres a la sisa y millón y los restantes diez y nueve a las alcavalas y zientos. Cuya separazión pareze proporcionada y acomodada según su vezindad, frutos, ventas y consumos..." (cap. XI), aconsejando a los repartidores, con extrema precisión, cómo debían llevar a la práctica las instrucciones de la superintendencia (caps. XII y XIII), pudiendo reclamar al final de las mismas aquellos contribuyentes que se sintieran agraviados (cap. XIV) o que requiriesen justificante (cap. XV).

Los impuestos, generalmente, se pagaban por el citado procedimiento del repartimiento; es decir, la cantidad total con que el pueblo debía contribuir por un concepto concreto se prorratea entre los vecinos (51). El sistema acarreaba graves injusticias si no se actualizaba periódicamente el padrón de cobranza y de ahí el interés en formular claras y sucintas normas sobre la forma de realizar dichos repartimientos.

La confusión reinante, en los años inmediatos a la Nueva Planta, queda patente, en el marquesado, por los insistentes requerimientos del juez de residencia a los cobradores de los repartimentos para que liquiden el período que quedó pendiente entre 1706 - 1707 (cap. XXVII).

Pero, sobre todo, debemos insistir en el interés de estas normativas sobre cualquier tipo de exacción, bien sean reales o señoriales. Es incuestionable que tanto al rey como al señor les interesa, primordialmente, controlar los impuestos.

Insistentemente, minuciosas directrices señalan cómo los diputados para cuentas deben tomarlas a los vecinos señalando la trayectoria que debían llevar las cuentas de 
haberes reales, su ejecución e imprescindible aprobación por el gobernador (cap. XIX), dictando normas tales como que: "los ejecutores que binieren por dévitos de la Real Hacienda se les dé el cumplimiento por aquellos capitulares a cuyo cargo aya estado la cobranza del año que pidiere y no contra la villa y comunidad de vezinos como hasta aora han practicado con notable ynjustizia, pues con ningún pretexto se pueden gravar los vezinos con costas estando repartido el devito" (cap. XX).

Una vez analizadas las "Normas para el buen gobierno del marquesado" dictadas por el juez de residencia (año 1725) las cuales nos han aproximado al conocimiento de los elementos de control señorial y a los cambios impuestos tras la Nueva Planta, conviene, aunque no se profundice en el tema, recordar el aparente poder político que la nobleza valenciana gozaba en el Setecientos. La venida de los Borbones, en principio, favoreció al estamento nobilario que, endeudado y empobrecido a finales del XVI, supo sacar partido de acontecimientos históricos tales como expulsión de moriscos, Segunda Germanía y Guerra de Sucesión.

El duque de Gandía, al igual que otros nobles valencianos, apoyó la causa borbónica y esta actitud puso de manifiesto, una vez más, el trasfondo social de la contienda, pues la nobleza feudal y la oligarquía terrateniente de la ciudad de Gandía afianzaron sus intereses políticos en esta coyuntura, incrementados a través del monopolio del poder municipal. Resulta evidente que el campesinado quedó desamparado y en un primer momento "las clases medias sufrieron más que antes la marginación política al cerrarse, por el momento, la posibilidad de compartir el poder político a nivel local" (52).

Como era de esperar, la fidelidad de la nobleza a la causa borbónica se vió recompensada. Algunos señores afianzaron sus derechos después de la Guerra de Sucesión con una clara participación del rey en su favor(53).

A riesgo de ser reiterativos cabe insistir en que a partir de 1707 los intereses de la aristocracia aparentemente se impusieron, marcando una época de conflictos y pleitos, consolidándose, teóricamente, los de los señores en la primera mitad del XVIII. Pero no debemos olvidar que en esta centuria las facultades señoriales han perdido significado. Recordemos que el gobernador del marquesado don Francisco Benlloch se lamenta de la facilidad con que los vecinos recurren a la Audiencia(54).

Por tanto, el duque de Gandía tras la Nueva Planta pudo continuar controlando los ayuntamientos del marquesado, control que fue perdiendo eficacia ante la oposición cada vez más fuerte de sus componentes, campesinos acomodados, promotores de los pleitos antiseñoriales iniciados en el señorío en fecha muy temprana (Catadau en 1734) (55).

Pese a ello, al menos en la forma, se mantuvo una continuidad administrativa. Citemos como ejemplo que en la toma de posesión de 1755, por don Francisco Mont como apoderado de don Francisco Alfonso Pimentel, conde duque de Benavente, se recoge el juramento de homenaje y fidelidad de los miembros municipales, con idénticos términos que en la época foral (56). Pero esto es la teoría, y no siempre ésta coincide con la práctica. 
En el año 1755 el ducado de Gandía pasó a engrosar el inmenso patrimonio de la casa de Osuna, por lo que su estructura administrativa se debió adaptar a la nueva situación. Si bien este hecho no supuso un cambio sustancial en su administración local, sí propició una creciente oposición por parte de los vasallos que, obviamente, veían resquebrajarse esa imagen panalista y cercana de su señor que, acertadamente, describe Atienza (57).

Por último, hay que destacar que hasta mediados del XVIII el control señorial en los municipios del marquesado se mantuvo firme. Recordemos, por ejemplo, que en el transcurso del pleito incoado por los vasallos de Catadau contra los derechos señoriales (27 de febrero de 1727) el fiscal reconoce los derechos, pero también las dificultades del pueblo a la reapertura de juicio: "nunca sería posible que el ayuntamiento, cuya justicia era del señor, con un alcalde mayor sobre ella puesto de su mano y con un procurador de la casa a la vista de todos diera tranquilamente los poderes contra el señor" (58).

Debemos mencionar que la situación en el último tercio del XVIII ya no es la misma. Un sector del campesinado local, terratenientes acomodados como José Bisbal, inevitablemente interfieren en la vida municipal recibiendo la crítica señorial en los siguientes términos: "los ayuntamientos manejados por algunos vecinos cuyos fines particulares pidieron obstinadamente la incorporación de Catadau a la Corona poseídos de su mala instrucción y temiendo que estas peticiones se repitan, ordena que avisen a sus moradores para que no vuelvan con sus pretensiones" (59).

El titular del señorío, don Luis Francisco de Borja Carroz y Centelles, consciente de la gravedad del momento, ordena se cumplan unos "Capítulos de buen gobierno del marquesado referentes a las regalías" (año 1773) justificándose en la "conservación de las rentas, como para la más recta administraciòn de justicia. Y por las turbaciones acaecidas no se mantienen en muchos de los lugares de los referidos estados o porque la malicia ha podido ocultarlos, o la injuria del tiempo ser causa de que hayan extraviado y no por tenerles presentes falle en mucha parte el mejor gobierno que podemos procurar..." (60).

Pese a estas medidas coactivas la postura antiseñorial de los municipios fue tomando consistencia y, tan sólo unos años después de estas advertencias (1776), el ayuntamiento de Alfarb y "otros oficiales locales" imponen una derrama para proseguir los pleitos contra el señor: "y salieron a cobrarla obligando a los vecinos de Alfarb a pagar y los que no tenían para pagar les recogieron algarrobas a bajo precio" (61).

En difinitiva, en el marquesado de LLombai, los municipios estuvieron desde siempre controlados por su señor. El titular del marquesado nombraba los cargos locales, pero su absentismo le obligaba a delegar parte de su jurisdicción en un procurador, baile, gobernador o alcalde mayor de su entera confianza que fiscalizaba cualquier actuación administrativa.

Con la pérdida definitiva del derecho foral valenciano, la potestad del duque de Gandía sobre la administraciòn local y territorial del marquesado queda indemne, 
pero el cambio histórico le obliga a adaptar el aparato administrativo al patrón marcado por la dinastía borbónica que, uniformadora por excelencia, toma los cargos e instituciones castellanas como modelo a seguir.

Dado que la documentacion de la residencia es una fuente inestimable de informacion sobre la administracion señorial, mecanismo de control que la nobleza toma de la administracion real como una forma más de inspeccionar la gestión de sus señoríos, nos hemos apoyado básicamente en las "Normas para el buen gobierno del marquesado" promulgadas a raíz del juicio de residencia de 1725 .

Su examen nos conduce necesariamente a una serie de conclusiones: En primer lugar pone en evidencia la similitud existente entre la administración real y la señorial; la nobleza, en nuestro caso el duque de Gandía, adopta el organigrama de las instituciones de la corona.

En segundo lugar debemos considerar que el marquesado, tras la Nueva Planta al igual que el resto de los señoríos valencianos, experimenta cambios importantes en lo que se refiere a la administración local, cuyos mandos de gobierno son sustituidos en conformidad con el modelo castellano basado en el "regimiento". El consell desaparece y, con él, el órgano de participación vecinal. Pero el nuevo ayuntamiento no asume competencias muy distintas a las asignadas al antiguo municipio de época foral, aunque aparecen nuevos cargos subalternos.

$Y$ en tercer lugar, como inicialmente se apunta, la intervención señorial se intensifica sobre la corporación municipal (edificio, sala capitular, archivo), pero donde se hace notar más contundentemente su mediación es cuando entran en juego sus intereses jurisdiccionales y económicos, fiscalizando las finanzas municipales en su provecho, aunque debemos insistir que quien efectivamente tiene el control en el XVIII es la Audiencia.

Otro aspecto importante a destacar es que, con la nueva institución, el marquesado de LLombai tuvo que soportar la introduccion de nuevas imposiciones reales. Esta mayor fiscalidad estatal, superpuesta a la municipal, señorial y eclesiástica, distanció, tanto aquí como en otros lugares valencianos, la situacion entre los vasallos de realengo y los de señorío en perjuicio de estos últimos que ya soportaban los gravámenes señoriales creando un clima propicio para la ya inminente oposicion antiseñorial.

Por último, no sería justo dejar de nombrar la inestimable aportación de don Francisco Benlloch, gobernador del marquesado al deslindar cargos, fijar responsabilidades y explicar las disposiciones del gobierno borbónico, quizá en un intento de clarificar una situación confusa, o simplemente por el deseo de congraciarse con su señor. 


\section{NOTAS}

1.- Archivo Histórico Nacional (A.H.N.): Sección Osuna. Leg. 722-6. FERRANDO i FRANCES, A.: LLibre del repartiment del regne de València. Vicent Garcia, Ed. S.A, Valencia, 1979.

2.- GOZALBEZ ESTEVE, E.: Análisis de un señorío valenciano: El marquesado de LLombai. Tesis doctoral inédita, Alicante, 1991. El marquesado de LLombai es un señorío cuyas tierras, desde el siglo XIV, que nos conste, fueron explotadas mediante el establecimiento a censo enfitéutico, con excepciones que no parecen tener gran importancia en el conjunto.

3.- A. H. N.: Sección Osuna. Leg. 588-37; 587; 594-17; 594-12.

4.- A. H. N.: Sección Osuna. Leg. 594-17; 588; 937-3.

5.- GOZALBEZ ESTEVE, E.: Análisis..., pp. 91-136.

6.- A. H. N.: Sección Osuna. Leg. 587, toma de posesión de 1530.

7.- Archivo Reino Valencia (A.R.V.): Sección Real Justicia. № 1683, libro 16, fol. 163, para Catadau. A.R.V.: Real justicia. Libro 28, $\mathrm{n}^{\circ} 5$, fol. 20, Varios 82-7, para Alfarb. A.R.V.: Real justicia. Libro 16, fols 477-482, para LLombai.

8.- GOZALBEZ ESTEVE, E.: "Capítols i ordenacions convenients i concernients del lloch de Catadau.". Dels Furs a l'Estatut. Actes del I Congrés d'Administració Valenciana: de la història a la modernitat. Generalitat Valenciana, Valencia, 1992, pp. 519-523.

9.- GOZALBEZ ESTEVE, E.: "Capítols i ordenacions...", caps. V, VII, VIII, XIII, XV y XVI.

10 - A. H. N.: Sección Osuna. Leg. 1.027. "Capítols fets per orde del poble per posar remei per a impedir que no se fasa dany en lo terme, fets aqui a 8 de abril en lo any 1614 ". Analizadas por PONS FUSTER: Aspectos económicos-sociales del condado de Oliva (15001750). Publicaciones del Ayuntamiento de Oliva, Valencia, 1981, pp. 193-195.

11.- GIMENEZ LOPEZ, E.: "El establecimiento del poder territorial en Valencia tras la Nueva Planta Borbónica". Estudis. (Valencia), nº 13. (1987), pp. 201-240. IRLES VICENTE, M". C.: "El control del municipio Borbónico. La reforma municipal de 1747 en Orihuela". Revista de Historia Moderna (Alicante), n² 8-9 (1988-90), p. 56.

12.- A. H. N.: Sección Osuna. Leg. 1.230. En las normas para el buen gobierno del marquesado de 1725, en el capítulo 8 se insiste en que los repartimentos "beneficios" y cobranzas de haberes deben ser "al estilo y normas con que los observan los pueblos de Castilla".

13.- GIMENEZ LOPEZ, E. e IRLES VICENTE, M" C.: "Los municipios de realengo valencianos tras la Guerra de Succesion". Estudis (Valencia), nº 17 (1991), pp. 75-114. PRADELLS NADAL, J.: "La Guerra de Succesió i la Nova Planta al País Valencià". Història del País Valencià. Edicions 62. Valencia, vol 1V, 1990, pp. 155-172.

14.- A. H. N.: Sección Osuna. Leg. 1.230. Las normativas de 1725 se refieren sólo a Llombai, pero el epígrafe se refiere a todo el marquesado. Desconocemos si éstas fueron aplicadas a todo el señorío o si se dictaron otras para los demás lugares.

15.- GONZALEZ ALONSO, B.: "Notas sobre las relaciones del estado con la administracion señorial en la Castillla Moderna". Anuario de la $H^{\underline{a}}$ del Derecho Español (Madrid), $\mathrm{n}^{\mathrm{o}}$ 53 (1983), pp. 365-399.

16.- CARRASCO MARTINEZ, A.: Control y responsabilidad en la administracion 
señorial. Los juicios de residencia en las tierras del Infantado (1650-1788). Universidad de Valladolid, Valladolid, 1991, pp. 9-21

17.- A. H. N..: Sección Osuna. Leg. 1.230, "Normas para el buen gobierno del marquesado".

18.- GIMENEZ CHORNET, V.: "Absolutisme i control dels oficials municipals al segle XVIII: El judici de residència a Cabanes". Estudis (Valencia), n²13 (1987), pp. 257-272.

19.- CARRASCO MARTINEZ, A.: Op. cit., p. 20.

20.- PLA ALBEROLA, P.: Conflictos jurisdiccionales en un gran señorio valenciano el condado de Cocentaina ante la consolidacion del absolutismo. Tesis doctoral inédita, Universidad de Alicante, 1985, pp. 534-549.

21.- A. H. N.: Sección Osuna. Leg. 1.281, Año 1778. Se nombró en el marquesado alcalde, regidor síndico, teniente de alcalde, alcalde de la hermandad y "este mismo año se hace bando público de los que han de ejercer cargos, y se les notifica a los capitulares actuales a fin de que aquellos hagan eleccion de los 24 electores a la conformidad mandada por el Real Consejo. SANTAYANA BUSTILLO, L.: Gobierno político de los pueblos de España. Instituto de Estudios de Administración Local, Madrid, 1979, pp. 17-23.

22.- GOZALBEZ ESTEVE, E.: "Crónica del fracaso de una repoblación: Alédua". Comunicación presentada a la Vl Asamblea de Història la Ribera. Alcira, abril 1993, (en prensa). Alédua quedó definitivamente despoblada con la expulsión de los moriscos en 1609.

23.- A. H. N.: Sección Osuna. Leg. 1.230. En el juicio de residencia de 1725 efectuado en el marquesado no se impone ninguna multa, simplemente se indica que si a partir de este juicio no cumplen lo ordenado serán sancionados con unas multas que oscilan desde 25 a 200 libras (Cap. III-VI-XXIX).

24.- BENLLOCH, F.: Op. cit., p 141.

25.- BENLLOCH, F.: Op. cit., pp 138-150.

26.- Referente a los regidores y a su indicada competencia en recaudar los impuestos tanto reales como municipales en el señorio con las instituciones borbonicas, cabe indicar que CARRASCO MARTINEZ (Op. cit.,.p. 114), respecto a Castilla, señala la conflictividad entre la administración real y la señorial con la nueva dinastía.

27.- A. H. N.: Sección Osuna. Leg. 722-6/14, Ordenanzas de 1.613, caps. XXXVIIXXXIX. BENLLOCH, F.: Op. cit., p. 143.

28.- BENLLOCH, F.: Op. cit., p. 144.

29.- BENLLOCH, F.: Op. cit., pp. 145-146.

30.- A.H.N.: Sección Osuna. Leg 722-6/14.

31.- CARRASCO MARTINEZ, A.: Op. cit., p. 47. ATIENZA, I.: "El señor avisado: programas paternalistas y control social en la Castilla del siglo XVII". Manuscrits (Barcelona), no 9 (1991), p. 172-195. Insiste en que ese control señorial del XVIII es un hecho "no sólo en Valencia sino también en Castilla".

32.- A. H. N.: Sección Osuna. Leg. 549-12.; 587-32.

33.- GOZALBEZ ESTEVE, E.: "Capítols i ordenacions...", p. 521.

34.- A.H.N.: Sección Osuna. Leg. 1.230. BENLLOCH, F.: Op. cit., p. 147.

35.- BENLLOCH, F.: Op cit., pp. 139-140.

36.- A.H.N.: Sección Osuna. Leg. 1.230. 
37 - BENLLOCH, F.: Op. cit., p. 134. A.H.N.: Sección Osuna. Leg. 695-232. La actuacion del gobernador o del alcalde mayor se vió en muchas ocasiones contestada por los vasallos. Los de LLombai se quejaron de que les privaran de vender libremente, acusando al alcalde mayor de ser el responsable de la pérdida de sus derechos.

38.- A.H.N.: Sección Osuna. Leg. 1.230, "Buen gobierno del Marquesado", año 1734.

39.- A.H.N. :Sección Osuna. Leg 723. BENLLOCH, F.: Op. cit., pp. 139-148. "La vara vale muy poco para vivir con la mayor estrechez pues atendiendo los tiempos muy caros el salario antiguo para ahora es muy corto los gajes ninguno. Sólo sobre el salario tiene el resto de gallinas, que ascenderá todo a seis pesos, tres por carga y media de garrofas, ocho pesos los tercios de penas y veinte que valdrá el tribunal, con que es visto que con el franco de casa, que se regula por doce pesos, vale líquido este gobierno ciento noventa y cinco pesos al año y no más. $Y$ esto en años que se trabaja y en el que no por no hacer que hazer prueba de la paz y tomar a la justicia lo judicial no vale diez pesos". A. H. N.: Sección Osuna. Leg. 1.086-29. Se insiste en el nombramiento de los Alcaldes Mayores por parte de la duquesa antes de 1812.

40.- ROLDAN VERDEJO, R.: Los jueces de la Monarquía Absoluta. Universidad de La Laguna, La Laguna, 1984. pp. 201-214.

41.- GIMENEZ LOPEZ, E.: "L'administració borbònica a València una administració militaritzada". Historia del País Valencià. Edicions 62, Valencia, 1990, volumen IV, pp. 173193 (la cita en p. 189).

42.- BENLLOCH, F.: Op. cit., p. 138. Algunos antecesores de don Francisco Benlloch fueron alcaldes mayores, como Luis Clavijo doctor en leyes al que acusa Benlloch de obrar corruptamente en el asunto de Bisbal (BENLLOCH, F.: Op. cit., p. 93-94). Luis Clavijo pasó después a procurador de la casa ducal de Gandía.

\section{3.- CARRASCO MARTINEZ, A.: Op. cit., p. 63.}

44.- Las irregularidades denunciadas eran las habituales en las visitas y residencias. Vid., por ejemplo, BERNABE GIL, D.: Monarquia y patriciado urbano en Orihuela, 1445-1707. Universidad de Alicante, Alicante, 1990, pp. 88-98.

45.- A.H.N.: Sección Osuna. Leg. 1.230.

46.- CARRASCO MARTINEZ, A.: Op. cit., p. 65.

47.- SANTAYANA BUSTILLO, L.: Op. cit., p. 36. Expone la importancia de las visitas en Castilla así como su introducción en la Corona de Aragón.

48.- A.H.N.: Sección Osuna. Leg. 695-220.

49.- Sobre la persistencia, durante la primera década del XVIII, de sisas e imposiciones municipales heredadas de época foral, véase IRLES VICENTE, M" C.: "El control del municipio borbónico. La reforma municipal de 1747 en Orihuela" Revista de Historia Moderna (Alicante), n 8-9 (1990), pp. 39-57. ALBEROLA ROMA, A.: "Centralismo borbónico y pervivencias forales. La reforma del gobierno municipal en la ciudad de Alicante (1747)". Revista de Historia Moderna (Alicante), $\mathrm{n}^{\circ} 18$ (1992), pp. 147-173. BRINES BLASCO, J. y PEREZ APARICIO, C.: "Aproximació al sistema impositiu de la ciutat de València (segles XVI al XIX)". Afers (Catarroja), nº 4 (1986), pp. 357-376.

50.- BENLLOCH, F.: Op. cit., pp. 133-134.

51.- CARRASCO MARTINEZ, A.: Op. cit., p. 61.

52.- MORANT DEUSA, I.: El declive del señorío. Institució Alfons el Magnànim, Valencia, 1984, p. 189. 
53.- RUIZ TORRES, P.: Señores y propietarios. Cambio social en el sur del País Valenciano: 1650-1850. Institució Alfons el Magnànim, Valencia, 1981.

54.- BENLLOCH, F.: Op. cit., p. 147.

55.- A. H. N.: Sección Osuna. Leg. 722-6. Es el primer documento analizado en el que Catadau presenta sus quejas y exige sus derechos de incorporación a la corona por vía judicial. A. GIL OLCINA (La propiedad señorial en tierras Valencianas. Del Cenia al Segura, Valencia, 1979, pp. 80-83), afirma que en la diferente forma de tenencia de la tierra "encuentra explicacion el marcado contraste entre la fuerte reaccion señorial que informa la segunda mitad del XVIII valenciano y la ausencia de un fenómeno similar para Castilla".

56.- A. H. N.: Sección Osuna. Leg. 591, toma de posesión de 1755.

57.- ATIENZA, I.: Op. cit., pp. 155-204.

58.- A. H. N.: Sección Osuna. Leg. 723, Memorial 1798. La comunicacion se hizo a los tres ayuntamientos y a "cada vecino" quedando archivada la relacion de todos los vecinos a los que se les comunicó la Real cédula de su majestad.

59.- A. H. N.: Sección Osuna. Leg. 723/722. El análisis de los cabreves del XVIII nos han permitido comprobar que los pobladores que apoyan a Bisbal eran campesinos acomodados, con cargos representativos en los ayuntamientos.

60.- A. H. N.: Sección Osuna. Leg. 1.264-28, "Capítulos de buen gobierno del marquesado de LLombai referentes a las regalías", 31 de mayo de 1773.

61.- A. R.V.: Real Acuerdo. Año 1776, nº 6. 